\title{
Good communication is key to good care
}

\author{
Sophie Cook UK research editor
}

The BMJ

For women with medical conditions the routine physical and emotional challenges of pregnancy are amplified by fluctuating symptoms and difficult treatment decisions that must balance risks and benefits to both mother and unborn child. Choosing the best option is rarely straightforward when drugs are needed. A discussion to consider the treatment options well before conception is helpful.

Valproate is a good example. An effective treatment for epilepsy, it is also licensed for bipolar disorder and, in some countries, migraine. But its teratogenic potential is well established, and there is no current agreement on the appropriate regulation of the drug in women who may become pregnant.

Recently, European and UK drug regulators strengthened their advice on use of valproate in this context ${ }^{12}$ : it should not be used unless a comprehensive "pregnancy prevention programme is followed." Our editorialists Angelika Wieck and Sarah Jones explain that the European Commission will soon decide whether to make these recommendations legally binding (doi:10.1136/ bmj.k1609). "A positive decision would be desirable and looks likely," they say.

The related analysis by Heather Angus-Leppan and Rebecca Liu (doi:10.1136/bmj.k1609) considers alternative approaches to valproate regulation, ranging from a ban to restricted availability. They emphasise that women should not be denied the human right to make their own decisions after fully informed discussion: "Banning valproate imposes less effective treatment for some female patients than for other people with a similar life threatening or serious condition, without their consent."

Good communication is central to good healthcare, and talking to colleagues is high on Margaret McCartney's agenda this week (doi:10.1136/bmj.k1602). She reflects on a time when colleagues communicated directly about patients, unlike today when referrals can be rejected simply for being on the wrong form. "People make the NHS; and people, in the end, are the only way to make it work" she says.

As our countdown continues to the NHS's 70th birthday, McCartney finds it "hard to escape the feeling that the NHS is in terminal decline." A new series of articles called Provocations will examine how to halt that decline and explore the NHS's future direction. We kick off this week with Mark Britnell (doi:10.1136/bmj.k1685), who argues that health leaders must engage with the productivity debate. Productivity "is about harnessing the talents of NHS staff" and is not to be feared, he says. Do join the debate online.

1 Medicines and Healthcare Products Regulatory Agency. New measures to avoid valproate exposure in pregnancy. Mar 2018. https://www.gov.uk/government/news/new-measuresto-avoid-valproate-exposure-in-pregnancy.

2 European Medicines Agency. New measures to avoid valproate exposure in pregnancy endorsed. Mar 2018. www.ema.europa.eu/ema/index.jsp?curl=pages/medicines/human/ referrals/Valproate_and_related_substances/human_referral_prac_000066.jsp\&amp; mid=WC0b01 ac05805c516f.\&lt;/eref.

Published by the BMJ Publishing Group Limited. For permission to use (where not already granted under a licence) please go to http://group.bmj.com/group/rights-licensing/ permissions 